\title{
Patterns of performance in amnesic subjects
}

\author{
J O H N C U T T I N G \\ From the Institute of Psychiatry and King's College Hospital, London
}

SUMMARY Patients with Korsakoff's syndrome, dementia, alcoholism, right and left temporal lobectomy, and normal subjects were compared on verbal learning and picture recognition memory tasks. Alcoholics and right lobectomy patients were similar on all measures, but the other groups had a characteristic pattern, particularly on hit and false positive rates in picture recognition.

A variety of clinical conditions give rise to a severe memory impairment-Korsakoff's syndrome (Korsakoff, 1889), third ventricular tumours (Grünthal, 1939), head injury (Friedman and Brenner, 1945), subarachnoid haemorrhage (Walton, 1953), tuberculous meningitis (Williams and Smith, 1954), bilateral temporal lobectomy (Scoville, 1954), and herpes simplex encephalitis (Rose and Symonds, 1960). Memory impairment may also occur as part of an intellectual decline. in dementia or chronic alcoholic deterioration. The term "amnesic syndrome" (Warrington, 1971) is widely used to convey the idea that the pattern of impairment is similar despite differences in the clinicopathological background. There are, however, reports of qualitative differences in memory arising in different clinical conditions. Compared to those with encephalitis, patients with Korsakoff's syndrome perform poorly on sequential memory (Lhermitte and Signoret, 1972) and semantic processing tasks (Cermak, 1976). Unlike dements, they are able to vary their performance according to the amount of interference and semantic material in a task (Butters et al., 1976), and show a different pattern of errors in verbal (Butters et al., 1976) and pictorial (Whitehead, 1975) recognition tests. A differential effect on the pattern of memory impairment is recognised between temporal lesions in opposite hemispheres: left sided damage affects verbal while right sided affects nonverbal material (Kimura, 1963).

These reports stimulated me to investigate the pattern of memory defect in a number of conditions. Five were chosen-Korsakoff's syndrome,

Address for reprint requests: Dr J. Cutting, Institute of Psychiatry, De Crespigny Park, Denmark Hill, London SE5, England.

Accepted 12 October 1977 dementia, chronic alcoholism, right, and left temporal lobectomy. The choice was determined by the known association of these conditions with memory defects, and by their availability. The most interesting group would have included patients with encephalitis or bilateral temporal damage but the rarity of these made the collection of 10 such patients impractical. Memory tests were chosen to contrast verbal and nonverbal performance across groups by measuring the scores on a paired-associate learning and a picture recognition test. These aspects of memory were selected to investigate the claim of Whitehead (1975) that Korsakoff's syndrome and dementia might be distinguished on the basis of their picture recognition scores, and to identify any discrepancy between verbal and nonverbal performance, which might indicate differences in hemispheric components. Further, in a picture recognition experiment, the memory process can be illuminated more fully by recording separately the hit rate and the false positives in addition to the conventional measure of the total correct score. The aim of the study was to test the hypothesis that performance on the tests by different groups would be heterogeneous.

\section{Subjects and methods}

There were six groups of 10 patients, all under 60 years of age. Normal subjects were hospital inpatients with extracerebral neurological disease (peripheral neuropathy or spinal cord lesions). Patients with Korsakoff's syndrome had an alcoholic background and were tested more than two months after the onset of a severe memory impairment when free of an initial "confusional state". Dements were included only if a pneumoencephalogram had revealed pathological enlarge- 
ment of the cerebral ventricles and the patient could understand the test instructions. Alcoholics had been abstinent for four weeks before testing and had been drinking heavily for at least 10 years. Patients with a left temporal lobectomy or a right temporal lobectomy had undergone their operation for temporal lobe epilepsy and were tested at a mean postoperative interval of 16 months. The sex distribution, mean age, and intelligence (Mill Hill Vocabulary Test) of subjects are shown in Table 1. The aim was to match all six groups on these three factors. Unfortunately, this was not possible for the lobectomy groups because of difficulty in obtaining sufficient numbers of subjects. Both had a lower mean age than other groups, and those with a left lobectomy had a different sex distribution and a lower verbal intelligence. Among the other groups the only appreciable difference was the lower current verbal intelligence of the dements.

The verbal memory test was an adaptation of the paired-associate learning subtest of the Wechsler Memory Scale. Ten pairs of words were read out twice, and after each presentation subjects were given the first members of the pairs and asked for the associates. In the Wechsler Memory Scale the pairs are divided into "easy" and "hard"; in my version all pairs were of intermediate difficulty and were selected from word association norms (Jenkins, 1970) so that the second member of a pair was the tenth most common association of the first-for example, soldier: march. The picture recognition test included 50 presentation items: 25 meaningless patterns (coloured photographs of histological specimens), and 25 simple objects. They were shown for three seconds each on 3 ins by 3 ins cards. Subjects were retested at a mean interval of three minutes for any item by shuffling the items with an equal number of fillers representing the same two categories. Subjects were asked to reply yes or no according to whether they recognised a picture as having been shown before. Two categories of pictures were presented in order to demonstrate any differences between ability to remember a fairly pure nonverbal item and one which was easily represented in words.

The results of the verbal memory test were ex- pressed as a percentage of the maximum possible score (20). Three measures of picture memory were calculated for each category-hit rate, false positive rate, and total correct score. These seven results were each analysed statistically by one-way analysis of variance across subject-groups. Following an overall significant effect, the means of each subject-group were compared by an a posteriori test. Duncan's test (1955) was chosen for this purpose-this is less rigorous than others available but some leniency in analysis was regarded as acceptable in order to emphasise the different patterns of impairment seen.

\section{Results}

There was a significant effect of subject-groups for all seven measures studied. In the case of pattern false positives the effect was at the $5 \%$ level only. Comparison of means was then carried out (Tables 2,3).

\section{KORSAKOFF'S SYNDROME}

Patients with Korsakoff's syndrome were inferior to normal subjects on all measures with the exception of false positives. From dements they differed only on their lower false positive rate on objects; there was a trend for fewer false positives to occur on patterns and for the verbal score to be lower. Compared with alcoholics they were worse on the verbal test and total correct objects; total correct patterns were comparable but this obscured significant differences in hit and false positive rates in opposite directions. The comparison with subjects having a right lobectomy resembled that made with alcoholics. Left lobectomies resembled normals in this comparison, with the exception of object false positives which emerged as significantly different in the Korsakoff-left lobectomy comparison.

\section{DEMENTS}

This group differed from normal subjects, alcoholics, and both lobectomy groups on total correct for both types of pictures, but, whereas on patterns a lower hit rate was largely responsible, on objects a higher false positive rate was characteristic. On the verbal test they were worse than all four

Table 1 General characteristics of groups studied

\begin{tabular}{lllllll}
\hline & Normal & Korsakoff & Dement & Alchoholic & Left lobectomy & Right lobectomy \\
\hline Sex $(\mathrm{m} / \mathrm{f})$ & $7 / 3$ & $7 / 3$ & $7 / 3$ & $7 / 3$ & $4 / 6$ & $7 / 3$ \\
Age $(\mathrm{yr})$ & 51 & 52 & 54 & 50 & 36 & 36 \\
Verbal IQ & 98 & 97 & 90 & 97 & 86 & 97 \\
\hline
\end{tabular}


Table 2 Mean scores (\%) of subject-groups on memory tests

\begin{tabular}{|c|c|c|c|c|c|c|}
\hline & Normal & Korsakoff & Dement & Alcoholic & Left lobectomy & Right lobectomy \\
\hline Verbal & 75 & 19 & 33 & 73 & 43 & 73 \\
\hline $\begin{array}{l}\text { Patterns } \\
\text { Hit rate } \\
\text { False positive } \\
\text { Total correct }\end{array}$ & $\begin{array}{l}77 \\
19 \\
79\end{array}$ & $\begin{array}{l}35 \\
11 \\
62\end{array}$ & $\begin{array}{l}40 \\
23 \\
59\end{array}$ & $\begin{array}{l}64 \\
27 \\
67\end{array}$ & $\begin{array}{l}70 \\
13 \\
79\end{array}$ & $\begin{array}{l}68 \\
31 \\
69\end{array}$ \\
\hline $\begin{array}{l}\text { Objects } \\
\text { Hit rate } \\
\text { False positive } \\
\text { Total correct }\end{array}$ & $\begin{array}{r}92 \\
3 \\
95\end{array}$ & $\begin{array}{l}65 \\
11 \\
77\end{array}$ & $\begin{array}{l}77 \\
21 \\
78\end{array}$ & $\begin{array}{r}81 \\
5 \\
88\end{array}$ & $\begin{array}{r}90 \\
2 \\
94\end{array}$ & $\begin{array}{r}86 \\
6 \\
92\end{array}$ \\
\hline
\end{tabular}

Table 3 Comparison of means-F values and significance

\begin{tabular}{|c|c|c|c|c|c|c|c|}
\hline & \multirow[t]{2}{*}{ Verbal } & \multicolumn{3}{|c|}{ Pattern } & \multicolumn{3}{|c|}{ Object } \\
\hline & & Hit & False positive & Total correct & Hit & False positıve & Total correct \\
\hline $\begin{array}{l}\text { Korsakoff/Normal } \\
\text { Korsakoff/Dementia } \\
\text { Korsakoff/Alcoholic } \\
\text { Korsakoff/Left lobectomy } \\
\text { Korsakoff/Right lobectomy } \\
\text { Dementia/Normal } \\
\text { Dementia/Alcoholic } \\
\text { Dementia/Left lobectomy } \\
\text { Dementia/Right lobectomy } \\
\text { Alcoholic/Normal } \\
\text { Alcoholic/Left lobectomy } \\
\text { Alcoholic/Right lobectomy } \\
\text { Left lobectomy/Normal } \\
\text { Left lobectomy/Right lobectomy } \\
\text { Right lobectomy/Normal } \\
\text { Overall F }\end{array}$ & $\begin{array}{c}45.4 \dagger \\
2.8 \\
44.0 \dagger \\
8.3^{*} \\
44.0 \dagger \\
25.6 \dagger \\
23.0 \dagger \\
1.4 \\
23.0 \dagger \\
0.0 \\
13.0 \dagger \\
0.0 \\
14.8 \dagger \\
13.0 \dagger \\
0.0 \\
17.0 \dagger\end{array}$ & $\begin{array}{c}18.9 \dagger \\
0.3 \\
8.6^{*} \\
13.3 \dagger \\
12.0 \dagger \\
14 .{ }^{+} \dagger \\
5.4 \\
9.5 \dagger \\
8.4^{*} \\
2.0 \\
0.5 \\
0.3 \\
0.5 \\
0.0 \\
0.8 \\
6.3 \dagger\end{array}$ & $\begin{array}{l}1.6 \\
3.4 \\
5.9^{*} \\
0.1^{*} \\
8.7^{*} \\
0.3 \\
0.3 \\
3.1 \\
1.2 \\
1.3^{*} \\
5.1^{*} \\
0.2^{2} \\
0.6^{*} \\
6.7^{*} \\
2.6^{*} \\
2.6^{*}\end{array}$ & $\begin{array}{c}17.6 \dagger \\
0.6^{\prime} \\
2.1 \\
16.9 \dagger \\
2.8^{-1} \\
25.3 \dagger \\
5.4^{*} \\
24.4^{*} \\
5.2^{*} \\
7.4^{*} \\
7.2^{*} \\
0.1 \\
0.1 \\
5.9^{*} \\
6.3^{*} \\
8.6 \dagger\end{array}$ & $\begin{array}{c}14.4 \dagger \\
2.8^{4} \\
4.7^{*} \\
12.0{ }^{*} \\
8.1^{*} \\
4.6^{*} \\
0.2 \\
3.1 \\
1.3 \\
2.6 \\
1.7 \\
0.4 \\
0.1 \\
0.4 \\
0.9 \\
3.8 \dagger\end{array}$ & $\begin{array}{c}3.6 \\
4.8^{*} \\
1.8 \\
4.8^{*} \\
1.1 \\
16.8 \dagger \\
12.6 \dagger \\
19.1 \dagger \\
10.8 \dagger \\
0.3 \\
0.4 \\
0.1 \\
0.1 \\
1.1 \\
0.7 \\
5.3 \dagger\end{array}$ & $\begin{array}{c}14.9 \dagger \\
0.1 \\
5.4^{*} \\
13.9 \dagger \\
10.6 \dagger \\
13.0 \dagger \\
4.6^{*} \\
12.1 \dagger \\
8.9 \dagger \\
2.3 \\
1.9 \\
0.9 \\
0.1 \\
0.2 \\
0.4 \\
6.0 \dagger\end{array}$ \\
\hline
\end{tabular}

* $P<0.05$

$+\mathbf{P}<0.01$

groups but not significantly so in comparison with the left lobectomy group.

\section{ALCOHOLICS}

Alcoholics resembled right lobectomies on all measures. They differed from normal subjects only on their total correct pattern score. They differed from left lobectomy subjects in obtaining a higher verbal score, a higher false positive rate on patterns, and a lower total correct pattern score.

\section{LOBECTOMIES}

The findings on patients with lobectomies were that, compared with normal subjects, left lobectomy patients had a poorer verbal memory while right lobectomy patients had a poorer total correct pattern score. Compared with each other, a left sided lesion led to a poorer verbal score, and a better total correct pattern score, for which a lower false positive rate was mainly responsible.

\section{Discussion}

VERBAL MEMORY

Patients with Korsakoff's syndrome, dementia, or left lobectomy were most impaired on this measure in comparison with the other three groups. Two points deserve emphasis. Verbal memory was preserved in alcoholics while pattern recognition was deficient. Secondly, although a comparison between subjects with Korsakoff's syndrome and dements failed to reach significance, the lower mean score in the former suggests that verbal memory might be particularly vulnerable in this group. These findings should be viewed with caution as there is a marked variation in clinical and pathological features in any group of dements, and the present suggestion may not be generally true.

PATTERN RECOGNITION MEMORY

On total correct score, subjects fell into three 
groups. Normal subjects and those with left lobectomies performed best, alcoholics and right lobectomy subjects intermediately, and Korsakoff's syndrome patients and dements worst. This pattern of results confirms Kimura's (1963) findings of a difference between left and right lobectomies on pattern recognition, and Clarke and Haughton's (1975) finding that alcoholics are impaired on visuospatial functions. The comparable scores of subjects with Korsakoff's syndrome and alcoholics, taken in conjunction with their disparate verbal scores, supports the idea of Butters and Cermak (1976), that the former have two neuropsychological deficits: one, mainly involving nonverbal ability, reflects their status as chronic alcoholics, and the other, affecting verbal and meaningful material, reflects the essential defect of Korsakoff's syndrome. The suggestion of Whitehead (1975) that performance on a picture recognition task might be a useful way of distinguishing Korsakoff's syndrome from dementia, was not supported, as, despite small differences in the means in the predicted direction, these were not significant.

\section{HIT RATE AND FALSE POSITIVES (PATTERNS)}

Analysis of the hit rate and false positives between groups revealed a number of relevant and, for the most part, novel findings. Some patterns emerged in comparisons, which were obscured in an analysis restricted to the total correct scores. Differences between groups could be attributed to different hit, but comparable false positive, ratesfor example, Korsakoff's syndrome versus left lobectomy-similar hit, but different false positive, rates-for example, left versus right lobectomyor moderate differences in both, which rendered the total correct score significantly different-for example, normal versus alcoholic, normal versus right lobectomy. A further situation occurred when significant differences in both, but in the opposite direction, cancelled each other out in the total correct score-for example, Korsakoff's syndrome versus alcoholic. The difference between the two lobectomy groups in the rate of false positives can be compared usefully with the work of Dimond (1976) on hemispheric components in an attention task. He found that in humans with a total commissurotomy, performance by the right hemisphere was characterised by a much greater false positive rate than applied to the other hemisphere. He suggested that this might be the effect of a more lenient criterion for the acceptance of stimuli. If it is justified to extrapolate from an attention task to the present experiment, it is intriguing that the right hemisphere working alone with sectioned commissures, and right temporal damage, both reduce the criterion adopted by a subject.

PICTURE RECOGNITION MEMORY FOR OBJECTS Patients with Korsakoff's syndrome or dementia were alone in their inferior performance on total correct score. In the former group this was mainly an effect of a lower hit rate, while dements made a large number of false positive responses. The good performance of subjects with right lobectomies and alcoholics, who had been inferior to normal subjects on patterns, may reflect a "ceiling effect" in the easier pictures of objects. It may, however, represent a genuine improvement for these groups if pictures have an identifiable verbal component.

\section{Conclusions}

The main aim of my study was to identify heterogeneity between groups. The absence of patients with bilateral hippocampal damage was unfortunate as it could be argued that only dements and patients with Korsakoff's syndrome were impaired enough to warrant the label "amnesic syndrome". Nevertheless, it is striking that among five conditions studied, only two, alcoholism and right lobectomy, were similar on all aspects examined. This in itself suggests that one of the effects of chronic alcoholism may be to impair right temporal functions. The pattern in these two groups was of normal verbal memory, and a moderately impaired pattern recognition memory with the highest rate of false positives. Subjects with left lobectomies had a moderately impaired verbal memory, and a normal picture recognition memory with a low rate of false positives. Dements had a poor verbal memory, and poor picture recognition memory with a high false positive rate. Korsakoff's syndrome subjects had the poorest verbal memory, and a poor picture recognition memory characterised by a low hit rate, and, on patterns the lowest false positive rate of any group. Although the idea of a uniform amnesic syndrome is not refuted, there are indications that memory impairment may be more heterogeneous than hitherto suspected.

\section{References}

Butters, N., and Cermak, L. S. (1976). Neuropsychological studies of alcoholic Korsakoff patients. In Empirical Studies of Alcoholism. Edited by G. Goldstein and C. Neuringer. Ballinger: Cambridge, Massachusetts. 
Butters, N., Tarlow, S., Cermak, L. S., and Sax, D. (1976). A comparison of the information processing deficits of patients with Huntington's chorea and Korsakoff's syndrome. Cortex, 12, 134-144.

Cermak, L. S. (1976). The encoding capacity of a patient with amnesia due to encephalitis. Neuropsychologia, 14, 311-326.

Clarke, J., and Haughton, H. (1975). A study of intellectual impairment and recovery rates in heavy drinkers in Ireland. British Journal of Psychiatry, 126, 178-184.

Dimond, S. J. (1976). Depletion of attentional capacity after total commissurotomy in man. Brain, 99, 347356.

Duncan, D. B. (1955). Multiple range and multiple F tests. Biometrics, 11, 1-42.

Friedman, A. P., and Brenner, C. (1945). Amnesticconfabulatory syndrome (Korsakoff's psychosis) following head injury. American Journal of Psychiatry, 102, 61-66.

Grünthal, E. (1939). Über das Corpus mamillare und den Korsakowschen Symptomkomplex. Confinia Neurologia, 2, 64-95.

Jenkins, J. J. (1970). The 1952 Minnesota Word Association Norms. In Norms of Word Association. Edited by L. Postman and G. Keppel. Academic Press: New York.
Kimura, D. (1963). Right temporal-lobe damage. Archives of Neurology (Chicago), 8, 264-271.

Korsakoff, S. S. (1889). A psychic disorder in conjunction with peripheral neuritis. Translated by $\mathbf{M}$. Victor and P. I. Yakovlev. Neurology (Minneapolis), 5, 394-406, 1955.

Lhermitte, F., and Signoret, J-L. (1972). Analyse neuropsychologique et differentiation des syndromes amnésiques. Revue Neurologique, 126, 161-178.

Rose, F. C., and Symonds, C. P. (1960). Persistent memory defect following encephalitis. Brain, 83, 195-212.

Scoville, W. B. (1954). The limbic lobe in man. Journal of Neurosurgery, 11, 64-66.

Walton, J. N. (1953). The Korsakov syndrome in spontaneous subarachnoid haemorrhage. Journal of Mental Science, 99, 521-530.

Warrington, E. K. (1971). Neurological disorders of memory. British Medical Bulletin, 27, 243-247.

Whitehead, A. (1975). Recognition memory in dementia. British Journal of Social and Clinical Psychology, 14, 191-194.

Williams, M., and Smith, H. V. (1954). Mental disturbances in tuberculous meningitis. Journal of Neurology, Neurosurgery, and Psychiatry, 17, 115123. 